\title{
AN INTEGRATED SHIFT SCHEDULE ASSESSMENT AND SELECTION PROCEDURE FOR POWER \& WATER PLANTS IN KINGDOM OF BAHRAIN
}

\author{
Hussain Abdali ABBAS \\ Al-Dur Power \& Water Plant \\ Bader Darwish AL MANNAI \\ University of Bahrain
}

\begin{abstract}
:
The continues increase in population and market globalization necessitated offering additional services and mass production strategy deployment. Consequently, a dramatic increase in research studies have been directed towards mitigating the shift schedule harmful physical, psychological, and social life effects on the workers. In addition, studies are currently conducted to determine the optimal shift schedule and shift rota, which is capable to incorporate human factors and applicable to the environment adopted in. In Kingdom of Bahrain there are no studies that investigate the effects of shift schedule on the operators, neither provide clear guidelines to select the appropriate shift schedule based on the environment adopted in. Accordingly, the aim of this paper is to present the development of an effective shift schedule selection mechanism that considers the physical, psychological, and social life factors for Al-Dur Power and Water Plant in Kingdom of Bahrain. The research methodology adopted was based on survey and case study. The results of this research study concluded that the shift schedule selection procedure developed was capable to involve all the stakeholders associated in the shift schedule selection process. In addition, it based the assessment and decision on the work environment adopted in.
\end{abstract}

Key words: shift schedule, human factors, power and water plant

\section{INTRODUCTION}

Worldwide countries have continuous rapid population growth and industrial development. To meet these uprising services and industrial demands created greater continuous operation and production implications on shift schedule and shift rota selection.

Shift schedule is defined as a form of work organization, in which two or a group of workers work in different time schedules (successions), to provide continuity in production [1]. It is the system of working in which work is carried out outside the normal day work hours (7:00 am-18:00 pm time frame) $[2,3,4]$.

Human factors discipline is one of the main aspects to consider, while deciding the shift schedule to be adopted in the organization [5]. Exposing them during the decisionmaking process will ensure effective shift selection, which comply with human capabilities and ensures mitigating the harmful physical, psychological, and social life effects on the operators $[6,7,8]$.
The current research studies are directed towards determining the optimal shift schedule and shift rota, which is capable to incorporate human factors and applicable to the environment adopted in $[9,10,11,12]$.

In Kingdom of Bahrain the shift schedule is a common experience for many workers, and it has different schedules and specifications. In addations Kingdom of Bahrain is one of the Gulf countries that is experiencing this raped increase in demand of services offered and continues industrial production [13].

One of the crucial areas that need strategic adjustments to accommodate theses increasing demands is the power and water plants. Accordingly, Kingdom of Bahrain has continuously upgraded and increased the number of power and water plants, and currently there are three power and water plants: Sitra Power \& Water Station, Hidd Power Company, and Al-Dur \& Water Plant.

Based on above, and the fact that nothing written in literature on how to establish an effective procedure to select 
the shift schedule for the power and water plants in Kingdom of Bahrain, the study was based on reviewing Al-Dur Power and Water Plant in Kingdom of Bahrain selection procedure and the number of shift schedule alterations.

Al-Dur Plant was selected as the case study for this study, as their shift schedule changed many times (five times during the period from 2012 to 2017), and the instability in shift schedule selection procedure caused continuous negative impact and complaints from shift workers.

\section{LITERATURE REVIEW}

Human factors are the study of the relationships between the employees and workplace according to particular environments, products, and services. They refer to environmental, organizational, and knowledge of human capabilities and limitations; in order to design a system, organization, job, machine, tool, or consumer product [14]. These definitions include three interrelated aspects:

- Job:

Includes company rules and policy, job procedures, distribution of responsibilities, the work environment, and the design of displays and controls. All these areas should comply with human capabilities and limitations.

- Organization:

Consists of the aspects that have a significant influence on individual and group behavior. These aspects are the cultures and norms of workplace, allocation of available resources, leadership styles, and communication.

- Individual:

Focuses on personnel attitudes and perception of understanding the rules and procedures. In addition, it examines how an employee is competent to carry out his/her responsibilities based on his/her experience, skills, knowledge and training.

The main purpose of enhancing human factors in an organization (through ensuring the best conditions in the workplace and ensuring work environment adaptation to human being skills, abilities, and limits) is to increase profit and reduce costs associated with work performance $[12,15]$.

Furthermore, human factors discipline has a prime impact on shift work, as it ensures the best selection of shift work schedule procedures that comply with human capabilities and limitations $[16,17]$. In shift work schedules, 8-hour shifts are designated as morning shift, afternoon shift and night shift; or simply shift 1 , shift 2 , and shift 3 . While, 12 hour shifts, shift work is designated as day shift or night shift [14]. The following techniques are adopted for arranging shift work schedules $[18,19,20]$ :

- Rotating Shift:

Many companies use rotational shift where a 24-hour day is divided into three 8-hour work shifts. This technique includes morning shift, evening shift and night shift. It is used by many companies, because it provides less subjective problems, no change in quantity and quality of sleep, and improves sleep quality for older workers.
- Alternating (partial) Rotation Shift: Where a worker rotates between two or three shifts in either forward or backward rotation.

- Fixed (permanent) Shift:

A fixed shift is the most common type in which a worker regularly works a single shift that includes five working days followed by two days off. Most workers prefer a fixed shift schedule, because it is easier for them to set a better plan for their family events. It also allows workers to proceed with higher education degrees, hold another job, and participate more in social activities. However, it raises many negative impacts. Fixed night shift lead to fatigue; due to lack of proper sleep.

- Compressed (12-hour) Shift:

The adoption of 12-hour shift (or compressed work week) is an alternative to the traditional shift schedules. In particular, 12-hour shift is accepted; because of many reasons: fewer switching or changeover from shift to another, fewer consecutive night shifts, and long frequent off weekends. This makes 12-hour shifts more attractive and can be an alternative to 8-hour shifts. However, long work hours might lead to excessive fatigue and sleepiness, which may result in higher risks of accidents and injuries in the short term, in addition to the deteriorations of health and well-being in the long term

- Flexible (flextime) Shift:

During the last few years, there has been growing interest in flexible arrangement of work hours during the day. This enables the employees to distribute the working hours per shift. The advantage of flextime shift is that it increases day-to-day free time, eases managing employees' personnel lives, enables developing professional careers, increases job satisfaction, reduces employee tardiness, fatiguing, and absenteeism. Conversely, flextime shift sometimes poses difficulties in scheduling meetings or training programs, leading to poor channels of communication within the organization, requiring more sophisticated planning, and additional supervision.

Even though, different shift schedule alternatives were applied internationally, there is vast evidence of inability to integrate human factors and work environment into the assessment and selection process, which negatively affected the overall work performance and employee welfare. Most of the reported studies indicated sleep disturbance, high absenteeism rates, high accident rates, health deteriorations, negative social impacts [21, 22, 23, 24, 25]. In Kingdom of Bahrain, around $40 \%$ of employees work on a shift basis in different companies, and there are existing problems in shift schedule selection procedures in most of these companies, specifically the Power and Water Plants [26]. 


\section{RESEARCH METHODOLOGY}

To accomplish the aim of this study, the research methodology adopted was based on data collection process, case study application, and expert review. The collection of data was based on reviewing the shift schedule process documents and archival records for Al-Dur Power and Water Plant in Kingdom of Bahrain. Consequently, developing the shift schedule selection procedure and implementation. Finally, the adoption of Delphi method to examine and evaluate the developed procedure and software package, by the Power and Water plants field experts and their top management (in Kingdom of Bahrain).

To define the current shift schedule selection procedure in Al-Dur Power and Water Plant, unstructured Face-toFace interviews were conducted with the plant Human Resources Department, Operations Department, and Union representatives. While, the case study application incorporated conducting structured Face-to-Face interviews with all the stakeholders associated with shift schedule review process and decision making.

The survey, on the other hand, was performed with Al-Dur shift workers, to capture their opinions regarding the current shift schedule and the selection procedure. The case study survey targeted Al-Dur Plant shift workers, who were affected from the shift schedule changes. The total number of shift workers in Operations Department is 43, which represented: Shift In-charge Engineers, Operations Engineers, Field Operations Engineers, and Shift Chemists. Out of the 43 shift workers, 6 shift workers joined recently, and they have not experienced the shift schedule changes. Accordingly, 37 shift workers were the survey sample population and 29 replies were received, corresponding to $78 \%$ response rate.

Based on the above a shift schedule selection decision making software package was developed. Furthermore, to ensure satisfactory stakeholders inclusion and comprehensive evaluation criteria, the shift schedule selection mechanism was formed utilizing risk assessment tool interlinked with fishbone diagram. The fishbone diagram, also known as Ishikawa diagrams, is a structured brainstorming technique that helps teams identify, explore, and visually display the possible causes related to an event. It focuses on facts, rather than judgmental decisions. In addition, it critically reviews processes, and creates a snapshot of the team's collective knowledge, which ensure capturing all possibilities and compiling them in one place [27].

Thereafter, the developed shift schedule selection Road Map and software package, was administered in Al-Dur Power \& Water Plant with the participation of the Human Resources Manager, the Operations Manager, the Maintenance Manager, the Head of Health and Safety Department, and the Labor Union representative.
Lastly, the expert review was administrated to review the implementation process results and validate the developed Road Map and software package. The experts selection process was based on the fact that they should have greater than ten years' experience in the field of power and water shift schedule selection procedure. Therefore, Al-Dur Power \& Water Plant Chief Financial Officer was invited to participate along with Sitra Power and Water plant Head of Operations Division, and Mondelez International Human Resources Business.

\section{AL-DUR POWER \& WATER PLANT SHIFT SCHEDULE SE- LECTION PROCEDURE DEVELOPED}

Based on the literature review, the Face-to-Face in-depth interviews with Al-Dur Power \& Water Plants top management, and the case study survey in the plant, the Shift Schedule Assessment and Selection procedure was developed (Fig. 1).

Figure 1 illustrates the three main stages: Planning Stage, Implementation Stage, and Evaluation Stage, constituting the Road Map.

\section{Stage 1: Planning Stage}

It involves five steps that demonstrate how the shift schedule change request will be processed from initiating the shift schedule change request until reaching the shift schedule change decision. It is initiated by raising a shift schedule change request from any of the following representatives (Human Resources, Operations, Labor Union, Health and Safety, and Maintenance), when the shift schedule causes excessive negative impact.

A presentation of change request is then conducted by the representative who raised the shift schedule change. The presentation demonstrates the complaints and reasons behind the shift schedule change initiation.

After conducting the presentation and realizing the need of shift schedule change, a team is assigned by the Plant General Manager (PGM). This team involves five representatives: Operations representative, Human Resources representative, Health and Safety representative, Maintenance representative, and Labor Union representative. The main responsibility of this team is to study the shift schedule change request, and apply the (planning, implementation, and evaluation) stages. Meeting 1 is then conducted between the five representatives.

In this meeting, the shift schedule selection software package is applied, to address the areas of concerns in the current shift schedule. 


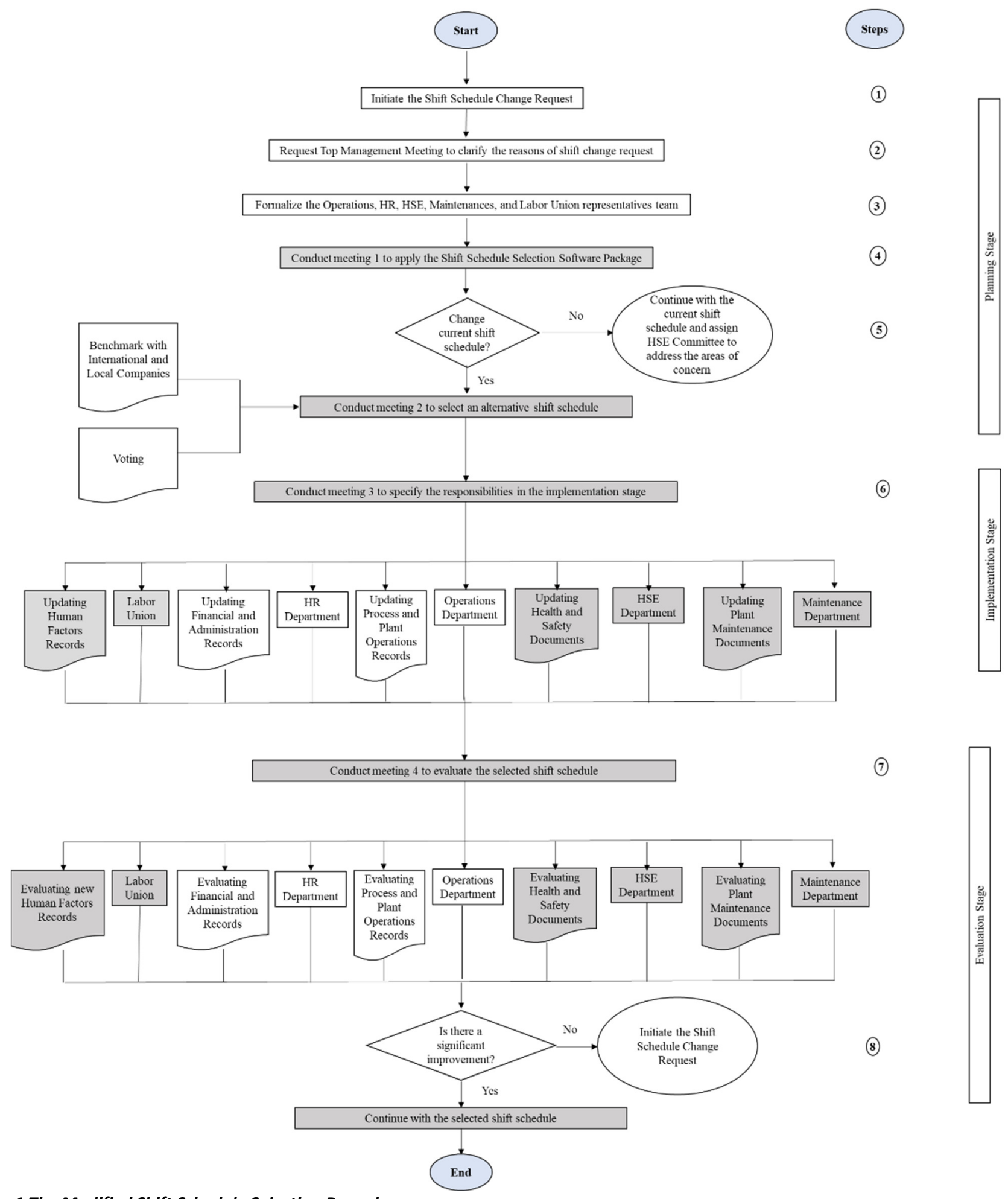

Fig. 1 The Modified Shift Schedule Selection Procedure

Each representative answers the questions in the risk assessment tool related to him or her.

- First sheet filled by the Labor Union representative, presenting the shift workers feedback, and it addresses the following sections (Table 1):

- Shift workers performance

- Health impact

- Social relationships
- Second sheet filled by the Human Resources representative, and it addresses the following sections (Table 2):

- Shift schedule policy

- Shift workers payroll

- Absenteeism Rate of Shift Workers

- Third sheet filled by the Operations representative, and it addresses the following sections (Table 3):

- The Plant Output \& Operations objectives 
- Shift workers traveling trips and shift switch

- Fourth sheet filled by Health and Safety representative, and it addresses the following sections (Table 4):

- Health and Safety objectives

- Shift worker Health and Safety records

- Fifth sheet filled by Maintenance representative, and it addresses the following sections (Table 5):

- Maintenance objectives
- The Plant Maintenance scheduling

Once the team representatives complete the assigned sheets, the results and analysis will be displayed in the Risk Assessment columns (Table 1 to Table 5), based on the risk assessment matrix (Table 6). Accordingly, the risk assessment columns, will provide a holistic view of the factors considered indicating their severity and probability.

Table 1

Labor Union Representative Sheet Results

\begin{tabular}{|c|c|c|c|c|c|c|c|c|c|c|c|c|c|c|}
\hline \multirow{4}{*}{$\begin{array}{c}\text { Questions } \\
\text { Section (A) Shift Workers Performance }\end{array}$} & & & & & & & & & & & Labor & & resenta & tive sneet Resul \\
\hline & \multicolumn{10}{|c|}{ Risk Assessment } & \multirow{2}{*}{\multicolumn{3}{|c|}{$\begin{array}{l}\text { \%Risk Assessment } \\
\text { Severity * Likelihood }\end{array}$}} & \multirow[t]{3}{*}{ Areas of Concern } \\
\hline & \multicolumn{5}{|c|}{ Severity } & \multicolumn{5}{|c|}{ Likelihood (Occurrance) } & & & & \\
\hline & 1 & 2 & 3 & 4 & 5 & 1 & 2 & 3 & 4 & 5 & $\begin{array}{l}1 \text { - } 4 \\
\text { (Low) }\end{array}$ & $\begin{array}{c}5-12 \\
\text { (Medium) }\end{array}$ & \begin{tabular}{|l|}
$15-25$ \\
(High) \\
\end{tabular} & \\
\hline $\begin{array}{l}\text { 1. What is the risk rate scale of the current shift } \\
\text { schedule on affecting the overall performance } \\
\text { negatively? }\end{array}$ & $\left.\begin{array}{c}6 \\
(21 \%)\end{array}\right)$ & $\begin{array}{c}2 \\
(7 \%)\end{array}$ & $\begin{array}{c}2 \\
(7 \%)\end{array}$ & $\begin{array}{c}7 \\
(24 \%)\end{array}$ & $\begin{array}{c}12 \\
(41 \%)\end{array} \mid$ & $\begin{array}{c}6 \\
(21 \%)\end{array}$ & $\begin{array}{c}2 \\
(7 \%)\end{array}$ & $\mid \begin{array}{c}2 \\
(7 \%)\end{array}$ & $\begin{array}{c}8 \\
(28 \%)\end{array}$ & $\begin{array}{c}11 \\
(38 \%)\end{array}$ & $27.60 \%$ & $6.90 \%$ & $65.50 \%$ & $\begin{array}{l}\text { Shift Workers } \\
\text { Overall Performance }\end{array}$ \\
\hline $\begin{array}{l}\text { 2. What is the risk rate scale of the current shift } \\
\text { schedule on causing time delays attendance on time to } \\
\text { the plant? }\end{array}$ & $\begin{array}{c}3 \\
(10 \%)\end{array}$ & $\begin{array}{c}7 \\
(24 \%)\end{array}$ & $\begin{array}{c}2 \\
(7 \%)\end{array}$ & $\begin{array}{c}8 \\
(28 \%)\end{array}$ & $\left|\begin{array}{c}9 \\
(31 \%)\end{array}\right|$ & $\left|\begin{array}{c}3 \\
(10 \%)\end{array}\right|$ & $\begin{array}{c}7 \\
(24 \%)\end{array}$ & $\mid \begin{array}{c}2 \\
(7 \%)\end{array}$ & $\begin{array}{c}8 \\
(28 \%)\end{array}$ & $\begin{array}{c}9 \\
(31 \%)\end{array}$ & $34.40 \%$ & $7.00 \%$ & $58.60 \%$ & $\begin{array}{l}\text { Shift Workers } \\
\text { Attendance }\end{array}$ \\
\hline $\begin{array}{l}\text { 3. What is the risk rate scale of the current shift } \\
\text { schedule on increasing the workload? }\end{array}$ & $\begin{array}{c}2 \\
(7 \%)\end{array}$ & $\begin{array}{c}15 \\
(52 \%)\end{array}$ & $\begin{array}{c}1 \\
(4 \%)\end{array}$ & $\begin{array}{c}8 \\
(28 \%)\end{array}$ & $\begin{array}{c}3 \\
(10 \%)\end{array} \mid$ & $\begin{array}{c}4 \\
(14 \%)\end{array}$ & $\begin{array}{c}14 \\
(48 \%)\end{array}$ & $\begin{array}{c}1 \\
(3 \%)\end{array}$ & $\begin{array}{c}7 \\
(24 \%)\end{array}$ & $\begin{array}{c}3 \\
(10 \%)\end{array}$ & $60.35 \%$ & $3.45 \%$ & $36.20 \%$ & \\
\hline \multicolumn{15}{|l|}{ Section (B) Health Impact } \\
\hline $\begin{array}{l}\text { 1.What is the risk rate scale of the current shift } \\
\text { schedule on causing digestion difficulties? }\end{array}$ & $\begin{array}{c}5 \\
(17 \%)\end{array}$ & $\begin{array}{c}5 \\
(17 \%)\end{array}$ & & $\begin{array}{c}10 \\
(35 \%)\end{array}$ & $\left|\begin{array}{c}9 \\
(31 \%)\end{array}\right|$ & $\begin{array}{c}5 \\
(17 \%)\end{array}$ & $\begin{array}{c}5 \\
(17 \%)\end{array}$ & & $\begin{array}{c}10 \\
(35 \%)\end{array}$ & $\begin{array}{c}9 \\
(31 \%)\end{array}$ & $34.40 \%$ & & $65.60 \%$ & $\begin{array}{c}\text { Experienced Digestion } \\
\text { Difficulties }\end{array}$ \\
\hline $\begin{array}{l}\text { 2. What is the risk rate scale of the current shift } \\
\text { schedule on causing appetite loss? }\end{array}$ & $\begin{array}{c}15 \\
(52 \%)\end{array}$ & & $\begin{array}{c}3 \\
(10 \%)\end{array}$ & $\begin{array}{c}4 \\
(14 \%)\end{array}$ & $\begin{array}{c}7 \\
(24 \%)\end{array}$ & $\begin{array}{c}15 \\
(52 \%)\end{array}$ & & $\begin{array}{c}4 \\
(14 \%)\end{array}$ & $\begin{array}{c}3 \\
(10 \%)\end{array}$ & $\begin{array}{c}7 \\
(24 \%)\end{array}$ & $51.70 \%$ & $12.05 \%$ & $36.25 \%$ & \\
\hline $\begin{array}{l}\text { 3. What is the risk rate scale of the current shift } \\
\text { schedule on causing an increase in headaches? }\end{array}$ & $\begin{array}{c}4 \\
(14 \%)\end{array}$ & $\begin{array}{c}3 \\
(10 \%)\end{array}$ & & $\begin{array}{c}14 \\
(48 \%)\end{array}$ & $\begin{array}{c}8 \\
(28 \%)\end{array}$ & $\begin{array}{c}2 \\
(7 \%)\end{array}$ & $\begin{array}{c}3 \\
(10 \%)\end{array}$ & & $\begin{array}{c}9 \\
(31 \%)\end{array}$ & $\begin{array}{c}15 \\
(52 \%)\end{array}$ & $20.70 \%$ & & $79.30 \%$ & $\begin{array}{l}\text { Increase in } \\
\text { Headaches }\end{array}$ \\
\hline $\begin{array}{l}\text { 4. What is the risk rate scale of the current shift } \\
\text { schedule on causing body fatigue? }\end{array}$ & $\begin{array}{c}1 \\
(4 \%)\end{array}$ & $\begin{array}{c}3 \\
(10 \%)\end{array}$ & & $\begin{array}{c}5 \\
(17 \%)\end{array}$ & $\mid \begin{array}{c}20 \\
(69 \%)\end{array}$ & $\begin{array}{c}1 \\
(4 \%)\end{array}$ & $\begin{array}{c}3 \\
(10 \%)\end{array}$ & & $\begin{array}{c}5 \\
(17 \%)\end{array}$ & $\begin{array}{c}20 \\
(69 \%)\end{array}$ & $13.80 \%$ & & $86.20 \%$ & Body Fatigue \\
\hline $\begin{array}{l}\text { 5. What is the risk rate scale of the current shift } \\
\text { schedule on causing mood fluctuation? }\end{array}$ & $\begin{array}{c}3 \\
(10 \%)\end{array}$ & & & $\begin{array}{c}12 \\
(41 \%)\end{array}$ & $\left|\begin{array}{c}14 \\
(48 \%)\end{array}\right|$ & $\begin{array}{c}3 \\
(10 \%)\end{array}$ & & & $\begin{array}{c}15 \\
(52 \%)\end{array}$ & $\begin{array}{c}11 \\
(38 \%)\end{array}$ & $10.30 \%$ & & $89.70 \%$ & Mood Fluctuation \\
\hline $\begin{array}{l}\text { 6. What is the risk rate scale of the current shift } \\
\text { schedule on causing sleep disturbance? }\end{array}$ & & $\begin{array}{c}1 \\
(3 \%)\end{array}$ & & $\begin{array}{c}10 \\
(35 \%)\end{array}$ & $\left|\begin{array}{c}18 \\
(62 \%)\end{array}\right|$ & & $\begin{array}{c}1 \\
(3 \%)\end{array}$ & & $\begin{array}{c}10 \\
(35 \%)\end{array}$ & $\begin{array}{c}18 \\
(62 \%)\end{array}$ & $3.40 \%$ & & $96.60 \%$ & Sleep Disturbance \\
\hline \multicolumn{15}{|l|}{ Section (C) Social Relationships } \\
\hline $\begin{array}{l}\text { 1. What is the risk rate scale of the current shift } \\
\text { schedule on causing difficulties to spend enough time } \\
\text { with family? }\end{array}$ & & $\begin{array}{c}2 \\
(7 \%)\end{array}$ & & $\begin{array}{c}10 \\
(35 \%)\end{array}$ & $\left|\begin{array}{c}17 \\
(59 \%)\end{array}\right|$ & & $\begin{array}{c}2 \\
(6 \%)\end{array}$ & & $\begin{array}{c}9 \\
(31 \%)\end{array}$ & $\begin{array}{c}18 \\
(62 \%)\end{array}$ & $6.90 \%$ & & $93.10 \%$ & $\begin{array}{l}\text { Prevents from } \\
\text { spending enough time } \\
\text { with family }\end{array}$ \\
\hline $\begin{array}{l}\text { 2. What is the risk rate scale of the current shift } \\
\text { schedule on causing difficulties to meet the family } \\
\text { commitments? }\end{array}$ & $\begin{array}{c}2 \\
(7 \%)\end{array}$ & $\begin{array}{c}3 \\
(10 \%)\end{array}$ & & $\begin{array}{c}9 \\
(31 \%)\end{array}$ & $\left|\begin{array}{c}15 \\
(52 \%)\end{array}\right|$ & $\left|\begin{array}{c}3 \\
(10 \%)\end{array}\right|$ & $\begin{array}{c}2 \\
(6 \%)\end{array}$ & & $\begin{array}{c}7 \\
(24 \%)\end{array}$ & $\begin{array}{c}17 \\
(59 \%)\end{array}$ & $17.20 \%$ & & $82.80 \%$ & $\begin{array}{l}\text { Difficulties to meet } \\
\text { family commitments }\end{array}$ \\
\hline $\begin{array}{l}\text { 3. What is the risk rate scale of the current shift } \\
\text { schedule on affecting the social relationships } \\
\text { negatively? }\end{array}$ & $\begin{array}{c}6 \\
(21 \%)\end{array}$ & $\begin{array}{c}1 \\
(3 \%)\end{array}$ & & $\begin{array}{c}8 \\
(28 \%)\end{array}$ & $\left|\begin{array}{c}14 \\
(48 \%)\end{array}\right|$ & $\begin{array}{c}5 \\
(17 \%)\end{array}$ & $\begin{array}{c}1 \\
(3 \%)\end{array}$ & & $\begin{array}{c}7 \\
(24 \%)\end{array}$ & $\begin{array}{c}16 \\
(55 \%)\end{array}$ & $22.30 \%$ & & $77.70 \%$ & $\begin{array}{l}\text { The social } \\
\text { relationships are } \\
\text { negatively affected }\end{array}$ \\
\hline
\end{tabular}


Table 2

Human Resources Representative Sheet Results

\begin{tabular}{|c|c|c|c|c|c|c|c|c|c|c|c|c|c|c|}
\hline Questions & \multicolumn{10}{|c|}{ Risk Assessment } & \multirow{2}{*}{\multicolumn{3}{|c|}{$\begin{array}{c}\text { \%Risk Assessment } \\
\text { Sererity * Likelihood }\end{array}$}} & Areas of Concern \\
\hline & \multicolumn{5}{|c|}{ Sererity } & \multicolumn{5}{|c|}{ Likelihood (Occurrance) } & & & & \\
\hline Section (A) Shift Work Schedule Policy & 1 & 2 & 3 & 4 & 5 & 1 & 2 & 3 & 4 & 5 & $\begin{array}{l}1-4 \\
\text { (Lom) }\end{array}$ & \begin{tabular}{c|c}
$5-12$ \\
(Medium)
\end{tabular} & $15-25$ (High) & \\
\hline $\begin{array}{l}\text { 1. What is the risk rate scale of the current shift } \\
\text { schedule on causing difficulties to comply with the } \\
\text { internal shift work schedule policy? }\end{array}$ & 1 & & & & & 1 & & & & & 1 & & & \\
\hline $\begin{array}{l}\text { 2. What is the risk rate scale of the current shift } \\
\text { schedule on causing difficulties to comply with the } \\
\text { Local Governmental shift work schedule policy? }\end{array}$ & 1 & & & & & 1 & & & & & 1 & & & \\
\hline \multicolumn{15}{|l|}{ Section (B) Shift Workers Payroll } \\
\hline $\begin{array}{l}\text { 1. What is the risk rate scale of the current shift } \\
\text { schedule on causing increase in shift workers over time } \\
\text { rate? }\end{array}$ & & 2 & & & & 1 & & & & & 2 & & & \\
\hline $\begin{array}{l}\text { 2. What is the risk rate scale of the current shift } \\
\text { schedule on causing difficulties to get enough Off } \\
\text { days? }\end{array}$ & 1 & & & & & 1 & & & & & 1 & & & \\
\hline \multicolumn{15}{|l|}{ Section (C) Absenteeism Rate of Shift Workers } \\
\hline $\begin{array}{l}\text { 1. What is the risk rate scale of the current shift } \\
\text { schedule on causing increase in the sick leaves by the } \\
\text { shift workers? }\end{array}$ & & 2 & & & & & 2 & & & & 4 & & & \\
\hline $\begin{array}{l}\text { 2. What is the risk rate scale of the current shift } \\
\text { schedule on causing increase in the annual leaves by } \\
\text { the shift workers? }\end{array}$ & 1 & & & & & 1 & & & & & 1 & & & \\
\hline $\begin{array}{l}\text { 3. What is the risk rate scale of the current shift } \\
\text { schedule on causing increase in the leaves without pay } \\
\text { by the shift workers? }\end{array}$ & 1 & & & & & 1 & & & & & 1 & & & \\
\hline
\end{tabular}

Table 3

Operations Representative Sheet Results

\begin{tabular}{|c|c|c|c|c|c|c|c|c|c|c|c|c|c|c|}
\hline Questions & \multicolumn{10}{|c|}{ Risk Assessment } & \multirow{2}{*}{\multicolumn{3}{|c|}{$\begin{array}{l}\text { \%Risk Assessment } \\
\text { Severity * Likelihood }\end{array}$}} & Areas of Concern \\
\hline & \multicolumn{5}{|c|}{ Severity } & \multicolumn{5}{|c|}{ Likelihood (Occurrance) } & & & & \\
\hline $\begin{array}{l}\text { Section (A) The Plant Output \& Operations } \\
\text { Objectives }\end{array}$ & 1 & 2 & 3 & 4 & 5 & 1 & 2 & 3 & 4 & 5 & $\begin{array}{l}1-4 \\
\text { (Low) }\end{array}$ & $\begin{array}{c}5-12 \\
\text { (Medium) }\end{array}$ & $\begin{array}{l}15-25 \\
\text { (High) }\end{array}$ & \\
\hline $\begin{array}{l}\text { 1. What is the risk rate scale of the current shift } \\
\text { schedule on affecting the overall plant output } \\
\text { negatively? }\end{array}$ & 1 & & & & & 1 & & & & & 1 & & & \\
\hline $\begin{array}{l}\text { 2. What is the risk rate scale of the current shift } \\
\text { schedule on preventing the Operations department } \\
\text { from achieving company objectives? }\end{array}$ & 1 & & & & & 1 & & & & & 1 & & & \\
\hline $\begin{array}{l}\text { 3. What is the risk rate scale of the current shift } \\
\text { schedule on causing difficulties to achieve } \\
\text { Operations department objectives? }\end{array}$ & 1 & & & & & 1 & & & & & 1 & & & \\
\hline $\begin{array}{l}\text { Section (B) Shift Workers Traveling Trips and } \\
\text { Shif Switch }\end{array}$ & & & & & & & & & & & & & & \\
\hline $\begin{array}{l}\text { 1. What is the risk rate scale of the current shift } \\
\text { schedule on increasing the number of traveling } \\
\text { trips to and from the plant? }\end{array}$ & & & 3 & & & & & 3 & & & & 9 & & \\
\hline $\begin{array}{l}\text { 2. What is the risk rate scale of the current shift } \\
\text { schedule on increasing the number of switching } \\
\text { from one shift to another? }\end{array}$ & 1 & & & & & 1 & & & & & 1 & & & \\
\hline $\begin{array}{l}\text { 2. What is the risk rate scale that the number of } \\
\text { traveling trips cause body fatigue due to the } \\
\text { current shift schedule? }\end{array}$ & & 2 & & & & 1 & & & & & 2 & & & \\
\hline $\begin{array}{l}\text { 4. What is the risk rate scale that the shift change } \\
\text { from Evening to Morning cause body fatigue? }\end{array}$ & & & & 4 & & & & & 4 & & & & 16 & $\begin{array}{l}\text { Shift Change from } \\
\text { Evening to Morning }\end{array}$ \\
\hline
\end{tabular}


Table 4

Health and safety Representative Sheet Results

\begin{tabular}{|c|c|c|c|c|c|c|c|c|c|c|c|c|c|c|}
\hline Questions & \multicolumn{10}{|c|}{ Risk Assessment } & \multirow{2}{*}{\multicolumn{3}{|c|}{$\begin{array}{c}\text { \%Risk Assessment } \\
\text { Sererity * Likelihood }\end{array}$}} & Areas of Concern \\
\hline & \multicolumn{5}{|c|}{ Severity } & \multicolumn{5}{|c|}{ Likelihood (Occurrance) } & & & & \\
\hline Section (A) HSE Objectives & 1 & 2 & 3 & 4 & 5 & 1 & 2 & 3 & 4 & 5 & $\begin{array}{l}1-4 \\
\text { (Low) }\end{array}$ & $\begin{array}{c}5-12 \\
\text { (Medium) }\end{array}$ & $\begin{array}{l}15-25 \\
\text { (High) }\end{array}$ & \\
\hline $\begin{array}{l}\text { 1. What is the risk rate scale of the current } \\
\text { shift schedule on preventing HSE department } \\
\text { from achieving company objectives? }\end{array}$ & & 2 & & & & 1 & & & & & 2 & & & \\
\hline $\begin{array}{l}\text { 2. What is the risk rate scale of the current } \\
\text { shift schedule on causing difficulties to } \\
\text { achieve HSE department objectives? }\end{array}$ & 1 & & & & & 1 & & & & & 1 & & & \\
\hline Section (B) Shift Worker HSE Records & & & & & & & & & & & & & & \\
\hline $\begin{array}{l}\text { 1. What is the risk rate scale of the current } \\
\text { shift schedule on increasing the shift workers } \\
\text { accidents? }\end{array}$ & 1 & & & & & 1 & & & & & 1 & & & \\
\hline $\begin{array}{l}\text { 2. What is the risk rate scale of the current } \\
\text { shift schedule on increasing the shift workers } \\
\text { high Potential Near Misses? }\end{array}$ & 1 & & & & & 1 & & & & & 1 & & & \\
\hline $\begin{array}{l}\text { 3. What is the risk rate scale of the current } \\
\text { shift schedule on increasing the shift workers } \\
\text { Occupational - illness reporting? }\end{array}$ & 1 & & & & & 1 & & & & & 1 & & & \\
\hline $\begin{array}{l}\text { 4. What is the risk rate scale of the current } \\
\text { shift change from Evening to Morning which } \\
\text { may lead to more accidents? }\end{array}$ & & & 3 & & & & 2 & & & & & 6 & & \\
\hline
\end{tabular}

Table 5

Maintenance Representative Sheet Results

\begin{tabular}{|c|c|c|c|c|c|c|c|c|c|c|c|c|c|c|}
\hline \multirow[b]{3}{*}{ Section (A) Maintenance Objectives } & \multicolumn{10}{|c|}{ Risk Assessment } & \multirow{2}{*}{\multicolumn{3}{|c|}{$\begin{array}{c}\text { \%Risk Assessment } \\
\text { Severity * Likelihood }\end{array}$}} & \multirow[t]{3}{*}{ Areas of Concern } \\
\hline & \multicolumn{5}{|c|}{ Severity } & \multicolumn{5}{|c|}{ Likelihood (Occurrance) } & & & & \\
\hline & 1 & 2 & 3 & 4 & 5 & 1 & 2 & 3 & 4 & 5 & $\begin{array}{l}1-4 \\
\text { (Low) }\end{array}$ & $\begin{array}{c}5-12 \\
(\text { Medium) }\end{array}$ & $\begin{array}{l}15-25 \\
\text { (High) }\end{array}$ & \\
\hline $\begin{array}{l}\text { 1. What is the risk rate scale of the current shift schedule on } \\
\text { preventing Maintenance department from achieving } \\
\text { company objectives? }\end{array}$ & 1 & & & & & 1 & & & & & 1 & & & \\
\hline $\begin{array}{l}\text { 2. What is the risk rate scale of the current shift schedule on } \\
\text { causing difficulties to achieve Maintenance department } \\
\text { objectives? }\end{array}$ & 1 & & & & & 1 & & & & & 1 & & & \\
\hline \multicolumn{15}{|l|}{ Section (B) The Plant Maintenance Scheduling } \\
\hline $\begin{array}{l}\text { 1. What is the risk rate scale of the current shift schedule on } \\
\text { causing delays in performing preventive Maintenance (PM) } \\
\text { jobs? }\end{array}$ & 1 & & & & & 1 & & & & & 1 & & & \\
\hline $\begin{array}{l}\text { 2. What is the risk rate scale of the current shift schedule on } \\
\text { causing delays in performing permit to work (PTW) } \\
\text { documents? }\end{array}$ & 1 & & & & & 1 & & & & & 1 & & & \\
\hline $\begin{array}{l}\text { 3. What is the risk rate scale of the current shift schedule on } \\
\text { causing delays in carrying out the operations routine jobs? }\end{array}$ & & & & & 5 & & & & 4 & & & & 20 & $\begin{array}{l}\text { Operations Routine } \\
\text { Jobs }\end{array}$ \\
\hline
\end{tabular}


Table 6

Risk Assessment Matrix Sheet

\begin{tabular}{|c|c|c|c|c|c|}
\hline \multirow{2}{*}{ Likelihood (L) } & 1 & 2 & 3 & 4 & 5 \\
\hline 5 & 5 & 10 & 15 & 20 & 25 \\
\hline 4 & 4 & 8 & 12 & 16 & 20 \\
\hline 3 & 3 & 6 & 9 & 12 & 15 \\
\hline 2 & 2 & 4 & 6 & 8 & 10 \\
\hline 1 & 1 & 2 & 3 & 4 & 5 \\
\hline \multicolumn{5}{l|}{} \\
$\begin{array}{l}\text { High } \\
\text { Medium } \\
\text { Low }\end{array}$ & \multicolumn{5}{l}{} \\
\hline
\end{tabular}

Furthermore, the shift schedule selection decision making mechanism software package was created with a purpose to interlink the risk assessment tool with the fishbone diagram.

The fishbone diagram will highlight the factors of concern/negative impact that need consideration to ensure effective shift schedule selection (Fig. 2).

Accordingly, if the decision made was to continue with the current shift schedule, the areas of concerns raised on the fishbone diagram should be reported to the Health and Safety Committee, which is mainly established to promote cooperation and effective communication between managers, staff and contractors. Thereby, ensuring effective arrangements to protect the worker's health, safety, and welfare at work. The Health and Safety Committee should report back with solutions minimizing the negative impacts. Whereas, if the decision made was to change the current shift schedule, the team should proceed to the implementation and evaluation stages.

\section{Stage 2: Implementation Stage}

It involves one step that demonstrate how the selected shift schedule will be applied. It is initiated by conducting a meeting to specify the responsibilities in implementation stage.
1. Human Resources Department Documents Modifications

The Human Resources representative modifies the following financial and administration documents, based on the new selected shift schedule:

- The Company Shift Policy.

- Operations Employees Payrolls and Absenteeism.

2. Operations Department Documents Modifications The Operations representative modifies the following process and plant operational documents, based on the new selected shift schedule:

- New Shift Timing re-scheduling.

- Shift Teams re-arrangement.

- New Plans for Operations Activities.

3. Health and Safety Department Documents Modifications

The Health and Safety representative modifies the following Health and Safety documents, based on the new selected shift schedule:

- Updating Operations Accident Records.

- Updating Operations Occupational - Illness Record.

4. Maintenance Department Documents Modifications The Maintenance representative modifies the following Plant Maintenance documents, based on the new selected shift schedule:

- Re-schedule Activities with Operations for Preventive Maintenance (PM) jobs.

- Re-schedule Activities with Operations related to Permit to Work (PTW).

5. Labor Union-Human Factors Records Modifications The Labor Union representative modifies the following human factors records, based on the new selected shift schedule:

- Updating criteria to measure health impact.

- Updating criteria to measure social relationships impact.

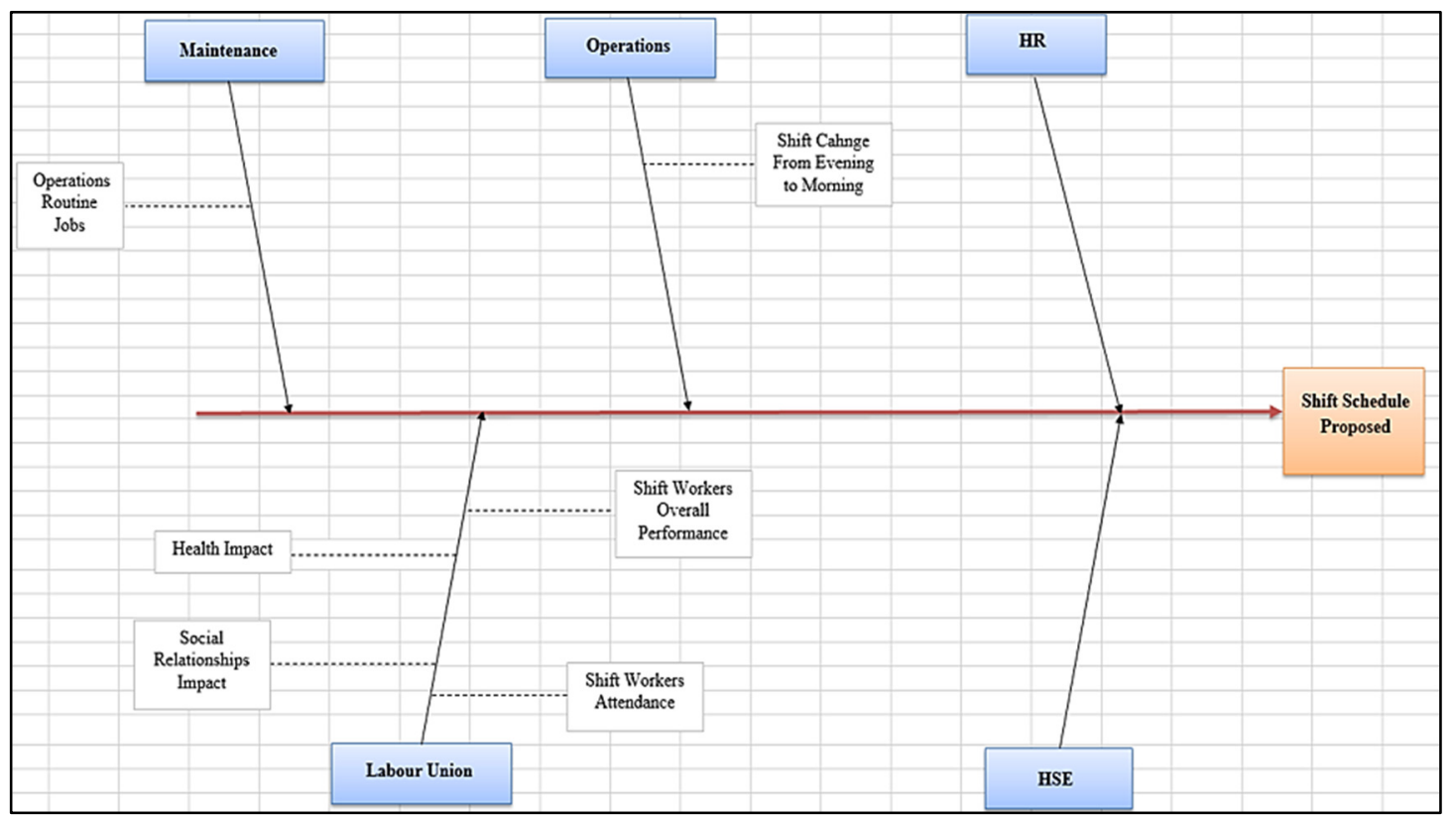

Fig. 2 Fishbone Sheet 


\section{Stage 3: Evaluation Stage}

It involves two steps that demonstrate how the selected shift schedule will be evaluated. It is initiated by conducting a meeting to specify the responsibilities in evaluation stage.

1. Human Resources Department Documents Evaluation The Human Resources representative evaluates the following financial and administration documents, based on the new selected shift schedule:

- Operations Employees Payrolls.

- Rate of Shift Workers Absenteeism.

2. Operations Department Documents Evaluation The Operations representative evaluates the following process and plant operational documents, based on the new selected shift schedule:

- Operations Objectives.

- The Operations objectives (either individual personnel objectives or group objectives).

- The Plant Output.

3. Health and Safety Department Documents Evaluation The Health and Safety representative evaluates the following Health and Safety documents, based on the new selected shift schedule:

- Operations Accident Records.

- Operations Occupational - Illness Record.

4. Maintenance Department Documents Evaluation The Maintenance representative evaluates the following Plant Maintenance documents, based on the new selected shift schedule:

- Status of Scheduling PM Jobs.

- Status of Scheduling PTWs Jobs.

5. Labor Union Human Factors Records Evaluation The Labor Union representative evaluates the following human factors records, based on the new selected shift schedule:

- Status of Health Impact.

- Status of Social Relationships Impact.

Finally, based on the evaluation outcome, if the evaluation results analysis illustrates that there is a significant improvement; then the selected shift schedule continues. However, if the evaluation results analysis illustrates that there is minor improvement; then a new shift schedule change request should be initiated.

\section{RESULTS AND DISCUSSION}

The developed schedule selection procedure was implemented successfully and administered with the team representatives. The implementation process started from requesting the team representatives to fill-in the developed software package.

After the five representatives completed the corresponding sheets and the areas of concerns were displayed in the fishbone diagram (Fig. 2), a decision on the shift schedule change request had to be taken. Either to continue with the current shift schedule or change the shift schedule to a new shift schedule.

Based on the evaluation outcomes, the evaluation results analysis illustrated that 23 out of 37 factors (62\%) have low negative risk. Accordingly, the current shift schedule will continue.

In the shift schedule selection Road Map, Planning Stage -Step 5, if the decision outcome resulted to continue with the current shift schedule; the areas of concerns indicated on the fishbone diagram need to be addressed by the HSE Committee.

Accordingly, six areas of concerns relating to operations, maintenance, and labor union (Fig. 2), were investigated thoroughly by Al-Dur Plant Health and Safety Committee. The Committee had to review the 12 items rated as highrisk concerns and appropriate solutions were forwarded to the top management for implementation decisions.

At the end of the evaluation stage, the representatives were asked to comment on the shift schedule selection Road Map and software package applied. Overall a positive feedback was received from the representatives indicating the ease of executing the shift schedule selection procedure Road Map. In addition, they mentioned that the Road Map was comprehensive, and it addressed all the major areas in the concerned departments. Furthermore, they stated that the Road Map brought all the stakeholders in interactive sessions. While, the software package has ensured documented analysis and recommendations.

Finally, the expert review was utilized to review the developed Road Map and validate the implementation process results. The unstructured interview was conducted with field experts, selected based on experience (beyond ten years) in shift schedule process in power and water plants in Kingdom of Bahrain. Accordingly, the following participants were selected to take part in the unstructured interview: Al-Dur Power \& Water Plant Chief Financial Officer, Sitra Power and Water Station Head of Operations Division, and Mondelez Bahrain Human Resources Business.

The expert feedback was positive, supportive, and included the following recommendations to be considered in the future:

- Incorporation of focus continuous improvement ( $\mathrm{FCl}$ ) department (independent department) in the selection procedure. This department focuses on employee's development.

- To implement the developed shift schedule selection Road Map in Sitra Power and Water Station and Hidd Power Company and compare the results.

- To implement the developed Road Map in a different setting, such as: Fire Stations, Medical Centers, Aluminum Companies, and Gas and oil Plants.

- To complement the developed software application with Staff Scheduler Software Package, to facilitate staff shifts planning.

Overall, they praised the fact that the developed Road Map was able to efficiently structure the shit scheduling assessment and decision making in one process. In addition, the experts were very impressed with the software package developed, as it brought together all the stakeholders affected by the shift schedule selection process, 
and enabled the incorporation of the physical, psychological, and social life factors that are applicable to the surrounding environment.

Moreover, the experts noticed that when the decision taken was to continue with the current shift schedule, the areas of concerns highlighted on the fishbone diagram were further examined for reporting implementable solutions. According to them, this is a crucial step that ensures further actions will be taken and assigning this task to the Health and Safety Committee was an appropriate solution.

\section{RESEARCH LIMITATIONS}

The research scope was based on three power and water stations in Kingdom of Bahrain (Hidd Power Company, Sitra Power and Water Station and Aldur Power and Water Station). Al-Dur Plant was selected as the main case study for this research since it had the largest number of shift schedule changes compared with the rest. In addition, the modified shift schedule selection procedure was implemented in Al-Dur Power \& Water Plant and administered with their team representatives.

\section{CONCLUSION}

The aim of this study was to develop an effective shift schedule selection procedure that assess the physical, psychological, and social life factors associated with AlDur Power and Water Plant in Kingdom of Bahrain environment. The procedure incorporated a Road Map that linked the assessment process and decision making through a software package application. Positive results were achieved from implementing the Road Map in AlDur Plant, as it was recommended by Sitra Power \& Water Station Head of Operation division to proceed implementation in their Plant. Furthermore, reported solutions by Al-Dur Plant Health and Safety Committee are currently being forwarded to the top management for review and implementation decisions.

Although this study successfully achieved the set objective, there are opportunities for further research. Further in-depth investigation can be carried out to link the developed shift schedule selection Rod Map with shift rota selection software application. In addition, the shift schedule selection procedure implementation can be extended to similar environment that lack formal shift scheduling process.

\section{REFERENCES}

[1] T. Driscoll, R. Grunstein and N. Rogers. "A systematic review of the neurobehavioural and physiological effects of shiftwork systems." Sleep Medicine Reviews, vol 11(3), pp. 179-194, Jun. 2007.

[2] S. Gousheh "Aging and shiftwork tolerance." PhD. thesis, University of Toronto, Canada, 2000.

[3] L. Smith, S. Folkard, P. Tucker and I. Macdonald. "Work shift duration: A review comparing eight hour and 12 hour shift systems." Occupational and Environmental Medicine, vol. 55(4), pp. 217-229, Apr. 1998.
[4] G. Krueger. "Sustained work, fatigue, sleep loss and performance: A review of the issues." Work \& Stress, vol. 3(2), pp. 129-141, Apr. 1989.

[5] M. Othman, G. Gouw and N. Bhuiyan. "Workforce scheduling: A new model incorporating human factors". Journal of Industrial Engineering and Management, vol. 5(2), pp. 259-284, Nov. 2012.

[6] G. Costa. "The impact of shift and night work on health." Applied Ergonomics, vol. 27(1), pp. 9-16, Feb. 1996.

[7] G. Costa. "Factors influencing health of workers and tolerance to shift work." Theoretical Issues in Ergonomics Science, vol. 4(3-4), pp. 263-288, Jul.-Fec. 2003.

[8] J. Gärtnera, N. Musliuband and W. Slany. "Rota: A Research Project on Algorithms for Workforce Scheduling and Shift Design Optimization." Al Communications, vol. 14(2), pp. 83-92, Jul. 2001.

[9] J, Cañas, B. Velichkovsky and B. Velichkovsky. "Human Factors and Ergonomics" in IAAP Handbook of Applied Psychology. USA: John Wiley \& Sons, 2011, pp. 316-338.

[10] M. Boatca and B.Cirjaliu. "A Proposed Approach for an Efficient Ergonomics Intervention in Organizations." Procedia Economics and Finance, vol. 23, pp. 54-62, 2015.

[11] B. Carnahan, M. Redfern and B. Norman. "Designing safe job rotation schedules using optimization and heuristic search." Ergonomics, vol. 43(4), pp. 543-560, Apr. 2000.

[12] A. Miles. "The ergonomics and organizational stress relationship." PhD Thesis, Florida State University, USA, 2000.

[13] H. Naser. "Effects of Multi-Stage Flash and Reverse Osmosis Desalinations on Benthic Assemblages in Bahrain, Arabian Gulf." Journal of Environmental Protection, vol. 4(02), pp. 180-187, Feb. 2013.

[14] M. Helander. A Guide to the Ergonomics of Manufacturing. London: Taylor \& Francis, 1997, pp. 293-300.

[15] S. Merkus, A. Drongelen, K. Holte, M. Labriola, W. Mechelen and A. Beek. "The Association between Shift Work and Sick Leave". Occupational Environment Medical, vol. 69 (10), pp. 701-712. Oct. 2012.

[16] K. Kogi. Introduction to the problem of shiftwork. UK: Wiley, 1985, pp. 115-184

[17] A. Wagstaff and J. Sigstad. "Shift and night work and long working hours - a systematic review of safety implications." Scandinavian Journal of Work Environment and Health, vol. 37(3), pp. 173-185, May 2011.

[18] K. Viitasalo, E. Kuosma, J. Laitinen and M. Harma. "Effects of shift rotation and the flexibility of a shift system on daytime alertness and cardiovascular risk factors." Scandinavian Journal of Work, Environment \& Health, vol. 34(3), pp. 198-205, Jun. 2008.

[19] J. Axelsson, G. Kecklund, T. Åkerstedt and A. Lowden. "Effects of alternating 8- and 12-hour shifts on sleep, sleepiness, physical effort and performance." Scandinavian Journal of Work, Environment \& Health, vol. 24(3), pp. 62-68, Feb. 1998.

[20] R. Mitchell and A. Williamson. "Evaluation of an 8 hour versus a 12 hour shift roster on employees at a power station." Journal of Applied Ergonomics, Vol. 31(1), pp. 8393, Feb. 2000.

[21] G. laco. "The Consequences of Shift Work: Job Performance, Job Satisfaction, And Social Life." M. A. thesis, Concordia University, Canada, 1997.

[22] Y. Esquirol, B. Perret, B. Ruidavetse, J. Marquie, E. Dienne, M. Niezborala and J. Ferrieres. "Shift work and cardiovascular risk factors: New knowledge from the past decade." Journal of Archives of Cardiovascular Disease, vl. 104(12), pp. 636-668, Dec. 2011. 
[23] T. Kantermann, M. Jude, C. Vetter, T. Roeonneberg. "Shiftwork research: Where do we stand, where should we go?" Institute for Medical Psychology, vol. 8(2), pp. 95-105. Apr. 2010.

[24] B. Peplonska, W. Burdelak, J. Krysicka, A. Bukowska, A. Marcinkiewicz, W. Sobala, D. Muszynska and M. Rybacki. "Night shift work and modifiable lifestyle factors." Journal of Occupational Medicine and Environmental Health, 27(5), pp. 693-706. Sep. 2014.

[25] C. Ljosa and B. Lau. "Shiftwork in the Norwegian petroleum industry: overcoming difficulties with family and social life - a cross sectional study." Journal of Occupational Medicine and Toxicology, vol. 3, pp. 4-22, Aug. 2009.

\section{Hussain Abdali Abbas}

Department of Health, Safety \& Environment, Al-Dur Power \& Water Plant, Bahrain e-mail: Hussain-a.ali@hotmail.com

\section{Bader Darwish Al Mannai}

University of Bahrain

Department of Mechanical Engineering, Bahrain

e-mail: balmannai@uob.edu.bh
[26] M. Alawainati. "Considering life work balance in selecting the most appropriate shift timing for Alezzel Company". M. A. thesis, Open University Malaysia, 2013.

[27] G. Ilie and CN. Ciocoiu. "Application Of Fishbone Diagram To Determine The Risk Of An Event With Multiple Cause". Management Research And Practice vol. 2(1), pp. 1-20, Mar. 2010. 